\title{
Effects of temperature fluctuation during in vitro phase on in vitro microtuber production in different cultivars of potato (Solanum tuberosum L.)
}

\author{
Mahmoud Otroshy · Farhad Nazarian • \\ Paul C. Struik
}

Received: 27 July 2008/Accepted: 27 May 2009/Published online: 11 June 2009

(C) The Author(s) 2009. This article is published with open access at Springerlink.com

\begin{abstract}
An experiment, including potato cultivars Gloria (very early), Marfona (mid-early) and Agria (late), was carried out to assess the effects of different temperatures during two phases of the day on in vitro potato microtuber production. Temperature significantly $(P<0.01)$ affected the percentage of cuttings that produced microtubers. The highest temperatures in either phase resulted in the lowest percentage of cuttings that produced microtubers. With lower temperature during either phase, we found more microtubers per cutting and larger microtuber sizes. The effects of temperature on individual microtuber weight were not statistically significant. However, increasing the temperature during different thermophases increased both length and weight of sprouts formed on the microtubers. Moreover, the highest temperatures resulted in the lowest levels of tuberization (as shown by bud status) and the largest sprout growth. The temperature amplitude had a significant effect as well: very large temperature amplitudes resulted in poorer tuber formation compared with smaller temperature amplitudes with the same average temperature. All three cultivars showed different responses with regard to the percentage of explants that produced microtubers. After
\end{abstract}

M. Otroshy ( $\square)$

Agricultural Biotechnology Research Institute of Iran (ABRII), P.O. Box 85135-487, Najafabad, Isfahan, Iran

e-mail: otroshy@yahoo.com

F. Nazarian

Agronomy and Plant Breeding Group, Faculty of Agriculture,

University of Lorestan, P.O. Box 465, Khorramabad, Iran

P. C. Struik

Department of Plant Sciences, Centre for Crop Systems

Analysis, Wageningen University, P.O. Box 430, 6700

Wageningen, The Netherlands
45 days of incubation, the percentage of explants producing microtubers, the number of microtubers and the length of the sprouts were significantly increased compared with 35 days of incubation. Nonetheless, the status of the microtubers (sprouted or not-sprouted) and the microtuber size did not change beyond 35 days of incubation. Polynomial analysis of temperature effects showed that almost all traits assessed showed a significant linear trend.

Keywords Potato - Solanum tuberosum L. · In vitro · Nodal cutting · Microtuber - Temperature ·

Temperature amplitude . Thermophase

\section{Introduction}

In vitro temperature can affect microtuber production (Wang and Hu 1982; Akita and Takayama 1994). Although the growth of micropropagated plantlets is optimal at $20-25^{\circ} \mathrm{C}$, microtuber formation is often best at (slightly) lower temperatures. According to Wang and $\mathrm{Hu}$ (1982) the average number of microtubers is lower at higher in vitro temperature $\left(28-28^{\circ} \mathrm{C}\right.$ day/night) than at lower temperature (20-20 ${ }^{\circ} \mathrm{C}$ day/night). The optimum temperature for in vitro tuberization has been suggested to be $20^{\circ} \mathrm{C}$ (Wang and $\mathrm{Hu}$ 1982) or between 15 and $18^{\circ} \mathrm{C}$ (Akita and Takayama 1994). Moreover, it has been suggested that with equal average temperatures, constant temperatures will give higher levels of microtuber formation than alternating day-night temperatures (Wang and $\mathrm{Hu}$ 1982). This negative effect of alternating temperatures is in strong contrast with findings of Bennett et al. (1991) who showed that diurnal temperature fluctuations were generally beneficial in whole plants. Although much work has been done on the effect of (both day and night) temperatures on the 
developmental physiology and growth of the potato crop, relatively little is known concerning the effects of temperature on microtuber production. There seems to be a controversy in the literature on the minimum and optimum temperatures for efficient microtuber production in potato. Moreover, the effects of alternating temperatures or diurnal temperature fluctuations have not yet been established. The purpose of this study is to contribute to our knowledge on optimal temperatures for in vitro microtuber production in the dark and on the effects of diurnal temperature fluctuations, thus helping to increase the efficiency of microtuber production systems.

\section{Materials and methods}

Plant material

Disease-free tissue cultured potato plantlets were obtained from the potato germplasm bank of Plant Research International (Wageningen, The Netherlands) and cultured at the tissue culture laboratory of the Laboratory of Plant Breeding of Wageningen University (Wageningen, The Netherlands). Three potato cultivars were used: Gloria (very early), Marfona (mid-early) and Agria (late). Nodal cuttings with one leaf node were taken from 5 weeks old in vitro plantlets and cultured on an MS (Murashige and Skoog 1962) standard medium, containing standard vitamins, $8 \%$ sucrose, $6 \mathrm{~g} \mathrm{l}^{-1}$ agar (micro agar) and $500 \mathrm{mg}^{-1} \mathrm{CCC}$ (chlormequat chloride). The $\mathrm{pH}$ of the medium was adjusted to 5.7 before adding the agar and before autoclaving; CCC was added to the media after autoclaving and before solidification. Thirty millilitres of media was dispensed to a $96 \times 16 \mathrm{~mm}$ sterilised glass petri dish. Each petri dish was divided into three parts and each part was allocated to a cultivar. Four viable nodes (discarding tops) of each cultivar were cultured in one part of the petri dish. All petri dishes were closed, using glass caps and sealed with household plastic foil. Petri dishes were randomly placed in the allocated cells mounted on the seed germination table (see below) for 45 days under fully dark conditions.

\section{The experimental facility}

In the past some new devices were designed to germinate seeds. These include the bell jar or Jacobsen-apparatus, the germination cabinet, the room germinator and the Rodewald-apparatus. Recently, however, a new and unique germination table was designed with 100 independently controlled temperature cells. We used this facility to incubate potato explants in the experiment investigating the effects of temperature regimes. The advantage of this facility is that many different temperatures regimes can precisely be controlled, monitored and imposed on batches of propagules. These 100 individually temperature-controlled cells are mounted on a table arranged in a $5 \times 20$ array, each cell is designed for one standard petri dish $(96 \times 16 \mathrm{~mm})$ containing seeds (or as in our case: cuttings). The cell is insulated with a rigid material to reduce heat transfer among cells and to surrounding air; power for cells is provided from a commercial power supply, temperature regimes are computer controlled. This device was located in a special dark room without normal light.

\section{Temperature treatments}

For each treatment, the temperature was lowest at 00:00 h (midnight) then gradually increased and it reached its highest value at 12:00 $\mathrm{h}$ noon (midday), it was then gradually decreased to its lowest at 0000 hours again. This process was routinely repeated every $24 \mathrm{~h}$. Each treatment was replicated four times. Two different thermal phases per day (per $24 \mathrm{~h}$ period) were set: Phase 1 and Phase 2. Phase 1 was the period from 0000 hours (midnight) till 1200 noon (midday) and Phase 2 was the period from 12:00 noon (midday) till 24:00 h (midnight). Different temperatures were set for Phases 1 and 2.

Temperatures during Phase 1 included 12, 14, 16, 18 and $20^{\circ} \mathrm{C}$ and temperatures during Phase 2 were $17,19,21$, 23, and $25^{\circ} \mathrm{C}$. Temperatures during Phase 2 were higher to mimic diurnal temperature fluctuations with a higher day temperature than the night temperature. All 25 possible combinations were included in the experiment. These treatments resulted in differences in average temperature, but also in different levels of temperature amplitudes, ranging from $1,3,5,7,9,11$ to $13^{\circ} \mathrm{C}$.

\section{Observations}

Measurements included the proportion of explants that produced microtubers, the number of microtubers per explant, the size of each microtuber, the status of the bud, the length of the sprout (or leafy shoot) that was formed when the microtuber did not remain dormant and the weight of the different structures. The proportion of explants that produced microtubers and the number of microtubers per explant were assessed to record the success rate of microtuber formation. These two parameters are usually closely linked as the number of microtubers per successful explant was usually one. The size and weight of microtubers were assessed to investigate additional effects on growth after tuberization. Again, size and weight were closely linked, but the records on size are likely to be more accurate than the records on weight. The status of the bud and the length of the sprout on the microtuber (when 
formed) were assessed to indicate how strong and continuous the level of induction was during the whole production cycle. Finally, the weight of the different structures was also assessed to get an impression about total productivity of the explants and thus their efficiency to utilize the substrate available.

Non-destructive measurements were done after 35 and 45 days after cutting. Destructive measurements were done 45 days after cutting. The status of the buds (to evaluate the degree of induction to tuberize of the explant) was quantified by using the following scale: 5 for non tuberization (without microtuber), 2 for a tuberized stolon and 1 for a sessile tuber (based on Ewing 1981; McGrady et al. 1986). This scoring system means that for the parameter status of bud (Table 1) lower values indicate a higher level of induction and higher values illustrate a lower level of induction.

\section{Experimental design}

The experiment was set up in a split-plot design with two main factors: temperature during Phase 1 with five levels $\left(12,14,16,18\right.$ or $\left.20^{\circ} \mathrm{C}\right)$ and temperature during Phase 2 with five levels $\left(17,19,21,23\right.$ or $\left.25^{\circ} \mathrm{C}\right)$. Three different varieties (Gloria, Marfona and Agria) were included as a split factor; batch duration (days after cutting) with two levels (35 and 45 days after starting the experiment) was included in the analysis as well. The 25 temperature treatment combinations were randomly assigned in four replications; thus, a total of 1,200 nodal cuttings were used: 5 temperatures of Phase $1 \times 5$ temperatures of Phase $2 \times$ 3 cultivars $\times 4$ replications $\times 4$ nodal cuttings for each cultivar per petri dish $=1,200$ nodal cuttings. Data were analysed by SAS statistical version 6.12 (SAS Institute Inc. 1996) computer software.

\section{Results and discussion}

\section{Effect of temperature during Phase 1}

The effect of temperatures during the period $0-12 \mathrm{~h}$ (Phase 1) was found significant on percentage of explants that produced microtubers, the number of microtubers per cutting, the size of the microtuber, the status of the bud, the length and weight of the sprouts and also the total propagule weight. However, there was no significant effect on the microtuber weight (Table 1). The lowest percentage of

Table 1 Effects of temperature during two different phases of the day, cultivar and batch duration on some characteristics of microtubers produced in the dark

\begin{tabular}{|c|c|c|c|c|c|c|c|c|}
\hline Traits & PE & NM & SM & SB & LS & WM & WS & WP \\
\hline \multicolumn{9}{|c|}{ Phase 1 temperature $\left({ }^{\circ} \mathrm{C}\right)$} \\
\hline 12 & $81 \mathrm{a}$ & $0.81 \mathrm{a}$ & $2.1 \mathrm{a}$ & $1.35 \mathrm{~b}$ & $10.0 \mathrm{c}$ & $7.5 \mathrm{a}$ & $10.5 b$ & $18.0 \mathrm{~b}$ \\
\hline 14 & $79 a$ & $0.79 \mathrm{a}$ & $2.0 \mathrm{ab}$ & $1.02 \mathrm{c}$ & $15.0 \mathrm{ab}$ & 7.1a & $15.6 \mathrm{ab}$ & $22.7 \mathrm{ab}$ \\
\hline 16 & $83 a$ & $0.84 \mathrm{a}$ & $2.0 \mathrm{ab}$ & $1.29 \mathrm{~b}$ & $17.7 \mathrm{a}$ & $7.3 \mathrm{a}$ & $19.0 \mathrm{a}$ & $26.3 \mathrm{a}$ \\
\hline 18 & $81 \mathrm{a}$ & $0.81 \mathrm{a}$ & $1.9 \mathrm{bc}$ & $1.24 \mathrm{bc}$ & $12.8 \mathrm{bc}$ & $6.7 \mathrm{a}$ & $15.9 \mathrm{ab}$ & $22.6 a b$ \\
\hline 20 & $68 \mathrm{~b}$ & $0.69 b$ & $1.7 \mathrm{c}$ & $1.57 \mathrm{a}$ & $17.8 \mathrm{a}$ & $6.5 \mathrm{a}$ & $20.4 \mathrm{a}$ & $26.9 \mathrm{a}$ \\
\hline \multicolumn{9}{|c|}{ Phase 2 temperature $\left({ }^{\circ} \mathrm{C}\right)$} \\
\hline 17 & $88 \mathrm{a}$ & $0.88 \mathrm{a}$ & $2.2 \mathrm{a}$ & $1.03 \mathrm{c}$ & $8.1 \mathrm{c}$ & $8.1 \mathrm{a}$ & $9.2 \mathrm{c}$ & $17.3 b$ \\
\hline 19 & $87 \mathrm{a}$ & $0.86 \mathrm{a}$ & $2.1 \mathrm{ab}$ & $1.26 \mathrm{bc}$ & $9.8 \mathrm{c}$ & $7.6 \mathrm{a}$ & $10.4 \mathrm{bc}$ & $18.0 \mathrm{~b}$ \\
\hline 21 & $76 b$ & $0.76 \mathrm{~b}$ & $1.9 \mathrm{bc}$ & $1.29 \mathrm{~b}$ & $14.1 \mathrm{~b}$ & $6.9 \mathrm{a}$ & $14.8 \mathrm{~b}$ & $21.7 \mathrm{~b}$ \\
\hline 23 & $77 b$ & $0.77 b$ & $1.8 \mathrm{c}$ & $1.24 \mathrm{bc}$ & $20.0 \mathrm{a}$ & $6.3 \mathrm{a}$ & $23.6 \mathrm{a}$ & $29.9 \mathrm{a}$ \\
\hline 25 & $64 \mathrm{c}$ & $0.66 \mathrm{c}$ & $1.6 \mathrm{~d}$ & $1.64 \mathrm{a}$ & $21.2 \mathrm{a}$ & $6.3 \mathrm{a}$ & $23.2 \mathrm{a}$ & $29.5 \mathrm{a}$ \\
\hline \multicolumn{9}{|l|}{ Cultivar } \\
\hline Gloria & $61 b$ & $0.61 b$ & $1.7 \mathrm{~b}$ & $1.62 \mathrm{a}$ & $12.9 b$ & $6.0 \mathrm{~b}$ & $21.0 \mathrm{a}$ & $27.0 \mathrm{a}$ \\
\hline Marfona & $88 \mathrm{a}$ & $0.89 \mathrm{a}$ & $2.6 \mathrm{a}$ & $1.12 \mathrm{~b}$ & $11.3 \mathrm{~b}$ & $11.1 \mathrm{a}$ & $14.4 b$ & $25.5 \mathrm{a}$ \\
\hline Agria & $86 a$ & $0.86 a$ & $1.5 \mathrm{c}$ & $1.15 b$ & $19.7 \mathrm{a}$ & $3.9 \mathrm{c}$ & $13.3 \mathrm{~b}$ & $17.3 \mathrm{~b}$ \\
\hline \multicolumn{9}{|c|}{ Batch duration (days) } \\
\hline 35 & $76 b$ & $0.76 b$ & 1.9 & 1.28 & $8.0 \mathrm{~b}$ & ND & ND & ND \\
\hline 45 & $80 a$ & $0.81 \mathrm{a}$ & 1.9 & 1.31 & $21.3 \mathrm{a}$ & 7.0 & 16.2 & 23.3 \\
\hline
\end{tabular}

Values followed by a similar letter are not statistically significantly different

$P E$ percentage of explants that produced microtubers, $N M$ number of microtubers per explant, $S M$ size of microtuber (mm), $S B$ status of bud (no dimension), $L S$ length of sprout (mm), WM weight of microtubers (mg), WS weight of sprouts (mg), WP weight of total propagule (mg), ND not determined 
explants that produced microtubers and the lowest number of microtubers per explant were associated with cuttings grown at the highest temperature during Phase $1\left(20^{\circ} \mathrm{C}\right)$. The other temperatures during Phase 1 (all below $20^{\circ} \mathrm{C}$ ) gave similar results. Microtubers were significantly larger at temperatures below $20^{\circ} \mathrm{C}$ during Phase 1 than at $20^{\circ} \mathrm{C}$ during this phase, but microtubers produced at $12^{\circ} \mathrm{C}$ during Phase 1 were also significantly larger than those produced at $18^{\circ} \mathrm{C}$ during Phase 1 . Lowest level of induction (non tuberization) was more often observed with $20^{\circ} \mathrm{C}$ during Phase 1 and the highest level of induction (highest frequency of sessile tubers) was found with $14^{\circ} \mathrm{C}$ (Table 1). Shortest sprouts were observed with lowest temperature during Phase 1 (Table 1). Highest values for length of sprout were obtained at 16 and $20^{\circ} \mathrm{C}$ (Table 1). Although the differences observed for microtuber weight were not statistically significant they were in agreement with the temperature effects on microtuber size (Table 1). Lowest value for weight of sprouts was observed at a Phase 1 temperature of $12^{\circ} \mathrm{C}$; cuttings exposed to the highest Phase 1 temperatures obtained highest values for weight of sprouts (Table 1). The overall weight of the developed bud was lowest at the lowest temperature (Table 1). This information is included separately in Table 1 as an indicator of the overall performance of the propagules and as the statistical analysis yielded different results for Phase 2 compared to the statistical analysis of the weight of microtubers and sprouts (see below).

\section{Effect of temperature during Phase 2}

Temperature during the period 12-24 h (Phase 2) significantly affected the percentage of explants that produced microtubers, the number of microtubers, the size of the microtuber, the status of the bud, the length and weight of the sprout originating from the microtuber and total propagule weight, but the effect on the weight of the microtubers was not significant (Table 1). The highest percentage of explants that produced microtubers and the highest number of microtubers per explant were associated with cuttings grown at the lowest temperatures during Phase 2 (17 and $19^{\circ} \mathrm{C}$ ). Temperatures above $20^{\circ} \mathrm{C}$ during Phase 2 gave poorer results. However, there were also significant differences between the treatment with $25^{\circ} \mathrm{C}$ during Phase 2 and the treatments with either 21 or $23^{\circ} \mathrm{C}$ during this phase (Table 1). The difference with the temperature response in Phase 1 is probably associated with the different range of temperatures installed during the two phases and shows the relevance of our approach.

There was a gradual effect of Phase 2 temperature on size of microtubers: the lower the Phase 2 temperature the larger the size (Table 1). A significant effect of Phase 2 temperature on the status of the bud was also observed: a Phase 2 temperature of $17^{\circ} \mathrm{C}$ caused more induction than Phase 2 temperatures 21 and $25^{\circ} \mathrm{C}$, whereas 19,21 and $23^{\circ} \mathrm{C}$ during Phase 2 resulted in better induction than the highest Phase 2 temperature (Table 1). Phase 2 temperatures also affected the length of the sprout, which developed on the microtubers. Increasing temperature promoted the length of the sprout: it was lowest with the lowest two temperatures, higher with $21^{\circ} \mathrm{C}$, and highest with the two highest temperatures $\left(23\right.$ and $\left.25^{\circ} \mathrm{C}\right)$ (Table 1). There was no significant effect of Phase 2 temperature on the microtuber weight (Table 1) but the trend matched the trend observed for size (Table 1). The effect of Phase 2 temperature on the weight of the sprout was also prominent. Cuttings treated with the highest Phase 2 temperature obtained highest values for sprout weight while it was lowest with lower temperatures and intermediate for the intermediate temperature (Table 1). The weight of the total propagule was significantly higher for 23 and $25^{\circ} \mathrm{C}$ than for the lower three temperatures (Table 1).

\section{Effect of diurnal fluctuation}

The difference between Phase 1 and Phase 2 temperatures showed a consistent relation with percentage of cuttings that produced microtubers, the number, size and weight of microtubers and the status of the bud. Although the relation was not always statistically significant due to outliers, the overall trend was consistent across variables (data not shown).

The number of microtubers became lower with a temperature differential above $9^{\circ} \mathrm{C}$. This suggests that combinations of too low temperatures of Phase 1 with too high temperatures of Phase 2 hampered microtuber formation and moderate temperatures throughout the $24 \mathrm{~h}$ period during the in vitro phase are required for microtuber formation. Smallest microtubers were produced when temperature differential was $5^{\circ} \mathrm{C}$ (an outlier) and when the diurnal fluctuation was above $11^{\circ} \mathrm{C}$. Lowest level of induction was observed when the temperature difference between Phase 1 and Phase 2 was $13^{\circ} \mathrm{C}$ while highest level was observed with a difference of $5^{\circ} \mathrm{C}$, thus confirming the results obtained for number of microtubers. Lowest weight of microtubers was obtained with temperature differences of 11 and $13^{\circ} \mathrm{C}$.

\section{Cultivar effects}

The percentage of explants that produced microtubers, the number of microtubers, the size and weight of microtubers, the status of the bud, the length and weight of sprouts and also the total propagule weight strongly differed among the three contrasting cultivars (Table 1). Gloria (the very early cultivar) produced the lowest number of microtubers. The 
largest and heaviest microtubers were found for Marfona while the smallest and lightest microtubers were obtained with Agria (Table 1). Despite its earliness, Gloria showed the poorest level of induction (Table 1). Agria produced the longest sprouts, but Gloria produced the heaviest sprouts (Table 1).

\section{Effect of batch duration}

No effect of batch time was found on the size of microtubers or the status of the bud but longer batch time increased the percentage of explants that produced microtubers, the number of microtubers and the length of sprouts (Table 1). Increasing batch time increased the percentage of explants that produced microtubers, number of microtubers per explant and the sprout length as well.

Phase 1 temperature $\times$ Phase 2 temperature interaction

The two-way interaction Phase 1 temperature $\times$ Phase 2 temperature was significant for the percentage of cuttings that produced microtubers, the number, size and weight of microtubers, and the status of the bud.

Effects of Phase 1 temperatures on number of microtubers were small at low Phase 2 temperature and considerably larger at Phase 2 temperatures above $21^{\circ} \mathrm{C}$. Phase 2 temperatures hardly had an effect when Phase 1 temperatures were $14-18^{\circ} \mathrm{C}$, but affected number of microtubers when Phase 1 temperatures were 12 or $20^{\circ} \mathrm{C}$ (data not shown). This suggests that moderate temperatures during the thermophase are required for proper microtuber formation and that too large differences in temperature during the thermophase are not beneficial. Similar observations on the interaction between temperatures were made for the percentage of explants that produced microtubers. Largest microtubers were obtained with temperature combinations in which the Phase 2 temperature was 17,19 or $21^{\circ} \mathrm{C}$. With high Phase 1 temperatures the effects of Phase 2 temperature were large, but did not show a consistent trend. Moreover with a Phase 2 temperature of $21^{\circ} \mathrm{C}$, effects of the Phase 1 temperature on size of microtubers were relatively large.

Temperature $\times$ cultivar interaction effects

The temperature $\times$ cultivar interactions for the percentage of explants that produced microtubers, the number of microtubers per cutting, the status of the bud and the length of sprout were all highly significant, for both Phase 1 temperature and Phase 2 temperature. Gloria proved to be more sensitive to higher Phase 1 and Phase 2 temperatures than the other two cultivars. This sensitivity was expressed by a stronger reduction of the number of microtubers and a much reduced expression of induction at the highest temperatures (data not shown). Yet, the Phase 1 and Phase 2 temperatures enhanced sprout growth much more in Agria than in the other cultivars.

Two-way interactions including the factor batch duration

The only significant two-way interaction including the factor batch duration was observed for length of sprout (interaction with Phase 2 temperature). The effects of Phase 2 temperature were better expressed after a long batch duration.

Three- and four-way interactions

The three-way interaction Phase 1 temperature $\times$ Phase 2 temperature $\times$ cultivar was highly significant for all parameters measured except for the length of the sprout, the weight of microtubers, the weight of sprouts and the total weight of propagule. However, the other three- or four-way interactions were not statistically significant.

\section{Polynomial analysis}

Given the equal intervals between temperatures during Phase 1 and Phase 2, polynomial contrasts were used to test the type of responses (linear, quadratic, cubic, etc.). The linear response was found significant $(P<0.01)$ for all traits except the weight of microtubers. The other response types were not found statistically significant. Since the linear model fitted most of the traits tested, it is recommended to use a regression model in order to predict how a specific cultivar behaves.

\section{Conclusions}

In general, we observed two critical temperatures for microtuber production. A clear threshold temperature was found as $20^{\circ} \mathrm{C}$. Crossing that threshold for the temperatures during Phase 1 or Phase 2 affected microtuber production. Temperatures during any of the two phases above $20^{\circ} \mathrm{C}$ gave a lower value for percentage of explants that produced microtubers or number of microtuber per explant. The second critical temperature could only be observed during Phase 2. A temperature of $25^{\circ} \mathrm{C}$ gave significantly fewer and smaller microtubers than $23^{\circ} \mathrm{C}$. Small diurnal temperature fluctuations gave slightly better performance than large diurnal fluctuations in temperature. Large fluctuations are definitely not beneficial compared with constant temperatures. 
Open Access This article is distributed under the terms of the Creative Commons Attribution Noncommercial License which permits any noncommercial use, distribution, and reproduction in any medium, provided the original author(s) and source are credited.

\section{References}

Akita M, Takayama S (1994) Induction and development of potato tubers in a jar fermentor. Plant Cell Tiss Organ Cult 36(2): $177-182$

Bennett SM, Tibbitts TW, Cao W (1991) Diurnal temperature fluctuation effects on potatoes grown with 12 hour photoperiods. Am Potato J 68:81-86
Ewing EE (1981) Heat stress and the tuberization stimulus. Am Potato J 58:31-49

McGrady JJ, Struik PC, Ewing EE (1986) Effect of exogenous applications of cytokinin on the development of potato (Solanum tuberosum L.) cuttings. Potato Res 29:191-205

Murashige T, Skoog F (1962) A revised medium for rapid growth and bio assays with tobacco tissue. Physiol Plant 15:473-497

SAS Institute Inc. (1996) SAS user's guide, 6.12 version. SAS Institute Inc., Cary, NC, p 494

Wang Po-jen, Hu Ching-yeh (1982) In vitro mass tuberization and virus-free seed potato production in Taiwan. Am Potato J 59: $33-37$ 